\title{
Supported Employment for Persons With Traumatic Brain Injury: A Preliminary Investigation of Long-Term Follow-Up Costs and Program Efficiency
}

\author{
Paul Wehman, PhD, John Kregel, EdD, Lori Keyser-Marcus, MA, Pam Sherron-Targett, MEd, \\ Leanne Campbell, BS, Michael West, PhD, David X. Cifu, MD
}

ABSTRACT. Wehman P, Kregel J, Keyser-Marcus L, Sherron-Targett P, Campbell L, West M, Cifu DX. Supported employment for persons with traumatic brain injury: a preliminary investigation of long-term follow-up costs and program efficiency. Arch Phys Med Rehabil 2003;84:192-6.

Objective: To investigate the long-term follow-up costs of supported employment as well as the wage and employment characteristics for individuals with moderate to severe traumatic brain injury (TBI) who participated in supported employment services over a 14 -year time period. data.

Design: Longitudinal design with prospectively collected

Setting: A university-based supported employment program that uses the individual placement model of supported employment.

Participants: Fifty-nine individuals with moderate to severe TBI who were consecutively referred for supported employment services. The sample was restricted to individuals who were placed into a least 1 supported employment position during the study period.

Interventions: Not applicable.

Main Outcome Measures: Data were collected on clients placed into at least 1 competitive supported employment position from 1985 to 1999. Analyses were performed to examine the costs of supported employment, employment characteristics (eg, wages, length of employment), and benefit-cost ratios of supported employment for individuals with TBI.

Results: The average length of employment for the current sample was 42.58 months. Average gross earnings were $\$ 26,129.74$ for individuals during their entire duration of employment. Billing charges accrued for employment services averaged $\$ 10,349.37$. Individuals with TBI earned an average of $\$ 17,515$ more than the costs associated with their supported employment.

Conclusions: Our investigation provides additional support for the conclusion that supported employment is cost effective for individuals with disabilities, including individuals with TBI, and that the costs of supported employment decrease over time.

From the Department of Physical Medicine and Rehabilitation, Virginia Commonwealth University/Medical College of Virginia (Wehman, Cifu) and School of Education, Virginia Commonwealth University (Kregel, Keyser-Marcus, SherronTargett, Campbell, West), Richmond, VA.

Supported in part by the National Institute on Disability and Rehabilitation Research, US Department of Education (grant nos. H133A980026, H133B980036)

No commercial party having a direct financial interest in the results of the research supporting this article has or will confer a benefit upon the authors or upon any organization with which the authors are associated.

Reprint requests to Paul Wehman, PhD, Rehabilitation Research and Training Center, Virginia Commonwealth University, Box 842011, Richmond, VA 23284, e-mail: pwehman@atlas.vcu.edu.

0003-9993/03/8402-7171\$35.00/0

doi:10.1053/apmr.2003.50027
Key Words: Brain injuries; Employment, supported; Rehabilitation.

(C) 2003 by the American Congress of Rehabilitation Medicine and the American Academy of Physical Medicine and Rehabilitation

$\mathbf{T}$ RAUMATIC BRAIN INJURY (TBI) can result in a variety of problems, including cognitive deficits, impaired psychosocial functioning, and physical or sensory disabilities. The impact of these sequelae on employment is often detrimental. Research has shown that individuals with TBI often experience difficulty securing and/or returning to competitive employment postinjury and maintaining employment for extended periods of time. ${ }^{1-6}$ Estimates of the employment rate for persons with TBI range from around $20 \%$ to $50 \%$ depending on the severity of the injury, the prior work experience of the individual, and demographic characteristics (eg, age, education, socioeconomic status)..$^{2,3,7-9}$ Prior investigations ${ }^{10-12}$ have noted several negative psychosocial consequences of unemployment for individuals with TBI, including depression, decreased social functioning, and various physical ailments. Additionally, financial difficulties commonly exist; lost wages present increased economic burdens to families of individuals with TBI, as well as to society as a whole when dependence on public assistance results.

Supported employment services are often used to assist individuals with disabilities to secure and maintain employment. ${ }^{13-15}$ In recent years, the supported employment model has been applied successfully to individuals with TBI, greatly enhancing employability and employment rates postinjury. ${ }^{16-18}$ Supported employment is defined as "paid work, occurring in integrated settings, with the provision of ongoing support services." 19 Essential elements of supported employment services have been pay for real work, integration in the workplace with nondisabled coworkers, long-term ongoing supportive services to facilitate job retention, placement of individuals with severe handicapping conditions, and interagency cooperation and funding of these services. ${ }^{20}$ The individual placement model of supported employment uses a vocational specialist (or job coach) to assist the person with locating employment, and coordinating or providing on-the-job supports such as new employee skills training and/or identifying accommodations. Also, long-term follow-up services are offered throughout the person's employment. During this time, additional on-the-job assistance is available if needed, and, as indicated, select case management services related to off-the-job-site issues that if left unattended would impact job retention, are provided.

Supported employment continues to be a program in which there is an interest in efficiency of outcomes. Cost efficiency provides a comparison of the monetary benefits of a program versus costs. Cost-effectiveness measures the long-term results and achievements of services. If the value of a program's benefits exceeds the costs, the program is considered to be a good investment, or "cost-efficient." ${ }^{21}$ Previous research has 
shown that supported employment is cost efficient (as well as cost effective when compared with sheltered workshops) for individuals with all types of disabilities, including individuals with severe disabilities. ${ }^{21-28}$ Further, the cost efficiency of supported employment programs increases with each year of program operation, with the benefits of supported employment exceeding the costs by the fourth year of operation. ${ }^{21}$

Information regarding the long-term costs of supported employment services as well as the long-term benefits to consumers is crucial in determining the efficacy of supported employment in individuals with TBI. To date, research has not examined the long-term costs of providing supported employment to individuals with TBI. The goal of our investigation was to examine the costs associated with, as well as the wages earned from supported employment, and the length of employment for individuals with TBI who participated in a supported employment over a 14-year time period. More specifically, the questions we attempted to answer were (1) What is the average cost of supported employment services for individuals with TBI? (2) What is the average length of employment for individuals with TBI who have received supported employment services? and (3) How do benefits (ie, participant income) compare with costs of supported employment during a 14-year time period (from 1985 to 1999)?

\section{METHODS}

The current sample consisted of 59 individuals with TBI who were consecutively referred to the supported employment program at Virginia Commonwealth University's Rehabilitation Research and Training Center, between August 1985 to August 1999. All participants were placed into at least 1 supported, competitive position, by using the individual placement model of supported employment. To be eligible for services, individuals had to meet the following criteria: be of working age $(18-64 y)$ and have sustained a moderate to severe TBI, as indicated by length of coma greater than 24 hours or a

Table 1: Client Characteristics ( $N=59)$

\begin{tabular}{lr}
\hline \multicolumn{1}{c}{ Variable } \\
\hline Mean age \pm SD (y) & $32.6 \pm 8.4$ \\
Range & $20-57$ \\
Gender (\%) & \\
Male & 81.4 \\
Female & 19.6 \\
Race (\%) & 74.6 \\
White & 22.0 \\
African American & 3.4 \\
Hispanic & \\
Education (\%) & 23.2 \\
Less than high school & 41.1 \\
High school graduate or equivalent & 1.8 \\
Trade or technical school & 17.9 \\
Some college & 16.1 \\
College graduate & \\
Unknown ( $\mathrm{n}=3$ ) & \\
Preinjury work status (\%) & 71.4 \\
Full-time employment & 3.6 \\
Part-time employment & 1.8 \\
Student working & 12.5 \\
Student not working & 10.7 \\
Unemployed not student & \\
Unknown ( $\mathrm{n}=3$ ) &
\end{tabular}

Abbreviation: SD, standard deviation.
Table 2: Lengths of Employment and Client Earnings

\begin{tabular}{lc}
\hline \multicolumn{2}{c}{ Employment Outcomes } \\
\hline Mean months employed & 42.58 \\
Mean monthly earnings (\$) & 633.63 \\
Mean total earnings (\$) & $26,129.74$ \\
Cumulative months employed & 2426 \\
Cumulative earnings (\$) & $1,489,395$
\end{tabular}

Glasgow Coma Scale score of less than 13 on admission to the hospital. In addition, each client had to present clear indications of the need for ongoing vocational intervention to return to preinjury employment or to obtain and maintain new employment. These indications could come from the individual's postinjury employment history or from reports from his/her family, physician, or vocational rehabilitation counselor. Individuals were not screened out of the program on the basis of the nature or severity of cognitive, behavioral, or other impairments. However, all individuals who received services through supported employment were asked to abstain from using alcohol and other nonprescription drugs.

Data regarding client wages, length of employment, hours worked per week, and demographic information were collected prospectively by the employment specialist assigned to each client. Additionally, data regarding charges for supported employment services were provided by billing records, accessed through the Virginia Commonwealth University/Medical College of Virginia Associated Physicians' billing office.

\section{Data Analysis}

Descriptive statistics were calculated for length of employment, costs associated with supported employment services, and wages earned. Subgroup comparisons were also performed to examine the influence of length of employment $(<2 y$ and $\geq 2 y$ ) on wages and supported employment costs. For the purpose of our study, calculations were based on individual clients, not job placements. Therefore, employment and billing data were combined and averaged for individuals who were placed into more than 1 job over the study duration.

\section{RESULTS}

Descriptive statistics were computed on demographic characteristics of the sample and are presented in table 1 . The average age of participants was $32.6 \pm 8.4$ years; $81.4 \%$ were men, and $74.6 \%$ were white.

The majority of the sample $(91.7 \%)$ had sustained a severe TBI, as indicated by length of coma of more than 1 day. With regard to cause of injury, $67 \%$ of the sample were injured in vehicular crashes, $8 \%$ had acquired their injuries because of abuse or assault, $10 \%$ were injured in falls, $11 \%$ sustained their injuries from gunshot wounds, and mechanism of injury was classified as "other" for $4 \%$ of the sample. The majority of the sample $(71.4 \%)$ were employed full-time at the time of injury.

\section{Employment Characteristics}

Results of the employment calculations revealed that the average hourly wage for individuals in the current sample was $\$ 5.25$ (range $\$ 3.35-\$ 11.99 / \mathrm{h}$ ). Individuals worked anywhere from 8 to 44 hours a week, with an average of 30 hours a week. The average length of employment for the sample was 42.58 months (range, $<1-141 \mathrm{mo}$ ). Key employment outcomes are described in table 2. Over a 14-year period, the average length of employment was 42.58 months. Average monthly earnings were $\$ 633.63$, which is substantially higher than the reported 


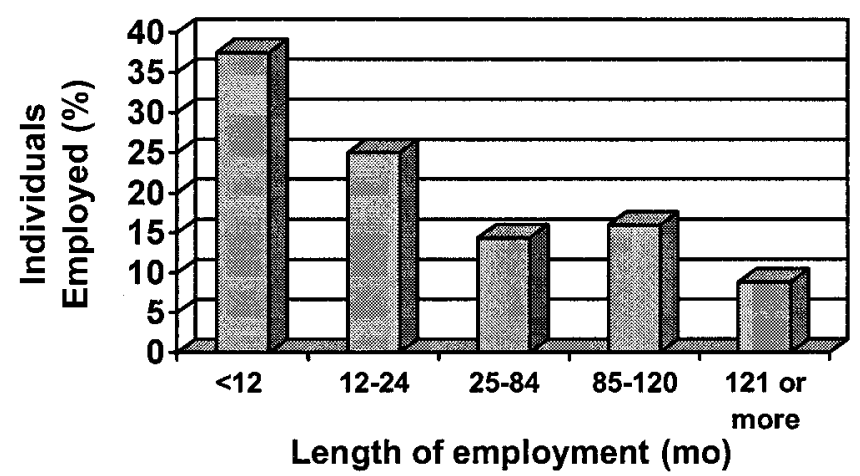

Fig 1. Employment retention over time.

earnings for other supported employment groups, and considerably higher than the Substantial Gainful Activity (SGA) threshold, which was in effect during the study time period. Data provided by the Rehabilitation Service Administration reported mean weekly earnings at closure for individuals with disabilities (not only TBI) who used supported employment services in fiscal year (FY) 1998 as \$142.93 (Rehabilitation Services Administration, unpublished raw data for FY 1997 and FY 1995).

Average gross earnings were $\$ 26,129.74$, with a range of $\$ 571.43$ to $\$ 168,290.57$ for individuals during their entire duration of employment (across placements, when applicable). Ranges for length of employment and gross monthly earnings are displayed in figure 1 and table 3, respectively. In figure 1 the length of employment contains a skewed distribution. Over half of the sample worked less than 2 years $(24 \mathrm{mo})$. However, approximately $25 \%$ of participants worked for 7 years $(84 \mathrm{mo})$ or longer. In fact, nearly $10 \%$ of the sample was employed for 12 years $(144 \mathrm{mo})$ or longer. With regard to monthly earnings, nearly $82 \%$ of the sample were earning over $\$ 400$ per month (median earnings, $\$ 602 / \mathrm{mo}$ ), and $63 \%$ of all participants earned more than the SGA threshold in effect during the time of the study.

\section{Supported Employment Costs}

Billing charges accrued for employment services averaged $\$ 10,349.37$ (range, \$646.96-\$69,635.99). Average costs per person for employment services were also calculated and are displayed in table 4; mean program cost was $\$ 8614$. It is important to note that this figure includes all of the costs of supported employment services for individuals over the study period, resulting in a mean monthly program cost of $\$ 202$.

\section{Subgroup Cost-Earnings Comparisons}

The skewed nature of employment duration (see fig 1) prompted further examination of the data in the form of sub-

Table 3: Monthly Gross Earnings for Individuals in Supported Employment

\begin{tabular}{cr}
\hline \multicolumn{2}{c}{ Range of Monthly Earnings } \\
\cline { 2 - 3 } \$ Range & $\%$ \\
\hline $0-200$ & 3.6 \\
$201-400$ & 14.3 \\
$401-600$ & 28.6 \\
$601-800$ & 28.6 \\
$801-1000$ & 14.3 \\
1001 or more & 10.6 \\
\hline
\end{tabular}

Table 4: Costs of Supported Employment Services

\begin{tabular}{lr}
\hline \multicolumn{2}{c}{ Program Costs } \\
\hline Mean per person program costs (\$) & 8614 \\
Mean monthly program costs (per person) (\$) & 202 \\
Cumulative program costs (\$) & 491,032 \\
\hline
\end{tabular}

group comparisons. Average earnings and supported employment costs for individuals who were employed for 0 to 24 months (brief employment group) were compared with average costs and earnings of individuals who were employed for 25 months or more (extended employment group). Results of the computations revealed similar earnings levels between groups, with individuals in the brief employment group earning an average of $\$ 659.93$ per month, and individuals in the extended employment group earning an average of $\$ 567.26$ per month of employment $\left(t_{59}=1.31, P=.19\right)$. However, a $t$ test performed to compare billing costs between groups found significantly higher monthly employment service costs attributed to the brief employment group $\left(t_{59}=4.04, P<.01\right)$. Average cost per month of employment services was $\$ 1304.09$ for individuals in the brief employment group, whereas average monthly cost of employment services for individuals in the extended employment group was $\$ 156.05$.

\section{DISCUSSION}

The results of our investigation provide additional support for the conclusion that supported employment is cost effective for individuals with disabilities, including individuals with TBI, and that the costs of supported employment decrease over time. In an earlier study, Wehman et al $^{29}$ found that the mean annual expenditure of supported employment for individuals with TBI was $\$ 10,198$ for the first year. Conversely, the average annual costs of supported employment services in our current longitudinal investigation were \$8614, suggesting a savings over time. Findings from our prospective investigation also appear to support prior research suggesting that the earnings reported by individuals with TBI in supported employment far exceed the costs associated with supported employment services, ${ }^{30}$ as participant income was an average of $\$ 17,515$ greater than the cost of supported employment services received over the 14-year time period.

Results of the subgroup comparisons suggest that, although wages did not differ with regard to length of employment, the costs associated with supported employment services were significantly lower for individuals who maintain employment for 2 or more years. There are several potential explanations for these findings. One explanation may be that costs of supported employment decrease over time, as suggested by Kregel et al. ${ }^{21}$ An alternative explanation for the differences related to costs of supported employment between groups could be that the subgroup of individuals who were able to maintain employment for an extended duration $(\geq 2 y)$ were higher functioning than those who were employed only briefly, and thus did not require as much on-site support, and/or extent of services. A recent study by Keyser-Marcus et $\mathrm{al}^{1}$ showed strong associations between key demographic and functional variables and return to work after TBI. Similarly, demographic and/or functional characteristics may play a substantial role in long-term job retention as well. Unfortunately, our subgroup analyses were limited in measuring such differences between subgroups. Future investigations should focus on demographic and functional variables related to employment retention of individuals with TBI. 
It is important to note that although the findings of our investigation are encouraging, these results are only preliminary and are not representative of the range of costs that may be involved in supported employment services. For example, we did not include the costs of assistive devices or other accommodations that might be necessary for job placement and/or retention. Additionally, the costs incurred by services provided by medical, psychiatric, and other rehabilitation professionals (eg, physical therapists, speech therapists) were not considered in our investigation. Finally, individuals in our sample participated in supported employment services that had been established before their enrollment in services. Consequently, start-up costs for supported employment were not reflected in the current analyses. Therefore, emerging supported employment programs should anticipate higher costs in the early stages of program implementation than are reported here.

Although examination of monetary costs and benefits of supported employment for individuals with TBI is important with regard to allocation of funds and resources, it is imperative that rehabilitation professionals acknowledge the nonmonetary benefits of employment (eg, increased community integration, improved quality of life, increased self-esteem, increased levels of worker integration) for this population. Many individuals with TBI often express feelings of social isolation, worthlessness, and decreased self-esteem as a consequence of TBI. ${ }^{10-12}$ Research investigating the cost effectiveness of supported employment with individuals with mental illness has shown that supported employment had a positive impact on clients' mental health and may have even substituted for traditional mental health services. ${ }^{23,31}$ Future research should examine the impact of these intangible benefits of supported employment on individuals with TBI. Further, when computing benefit-cost ratios, information about intangible and nonmonetary benefits, fringe benefits (eg, health insurance, leave time), and costs including tax liability (federal, state, local) and public assistance (Social Security Income, Social Security Disability Insurance) should be considered. Research reveals a national growth in supported employment participation from FY 1986 through FY 1995. Participation rose from approximately 10,000 persons in FY 1986 to over 139,000 in FY 1995. This reflects a $16 \%$ annual growth rate from participant totals reported in FY 1993. ${ }^{32}$ These data indicate that vocational rehabilitation agencies and other funding sources are turning to supported employment with increasing frequency. However, emphasis is on serving individuals with mental retardation and mental illness labels. Focus also remains on serving people with mild and moderate levels of disability rather than those persons with the most severe disabilities.

\section{CONCLUSION}

Supported employment participation has expanded very little for persons with TBI. In FY 1995, only $1.7 \%$ of supported employment participants had a primary disability classification of TBI. ${ }^{32}$ Although it is encouraging to see some progress, many more funds now directed to segregated or work readiness types of programs need to be redirected to competitive employment efforts. Furthermore, individuals with TBI often do not have access to any type of long-term funds, and this must be included in the future long-range funding plans of states. Finally, supported employment programs are effective when provided by well-trained staff dedicated to understanding the needs of the person served as well as the business. Many programs are not adequately prepared to serve persons with TBI at this time.

\section{References}

1. Keyser-Marcus L, Bricout J, Wehman P, et al. Acute predictors of return to employment after traumatic brain injury: a longitudinal follow-up. Arch Phys Med Rehabil 2002;83:635-41.

2. Asikainen L, Kaste M, Sarna S. Predicting late outcome for patients with traumatic brain injury referred to a rehabilitation programme: a study of 508 Finnish patients 5 years or more after injury. Brain Inj 1998;12:95-107.

3. Curl RM, Fraser RT, Cook RG, Clemmons D. Traumatic brain injury vocational rehabilitation: preliminary findings for the coworker as trainer project. J Head Trauma Rehabil 1996;11(1):7585.

4. McMordie WR, Barker SL. The financial trauma of head injury. Brain Inj 1988;2:357-64.

5. Kreutzer J, Morton MV. Traumatic brain injury: supported employment and compensatory strategies for enhancing vocational outcomes. In: Wehman P, Moon S, editors. Vocational rehabilitation and supported employment. Baltimore: PH Brookes; 1988. p 291-311.

6. Brooks N, McKinlay W, Symington C, Beattie A, Campsie L. Return to work within the first seven years after head injury. Brain Inj 1987;1:5-19.

7. Burleigh SA, Farber RS, Gillard M. Community integration and life satisfaction after traumatic brain injury: long-term findings. Am J Occup Ther 1998;52:45-52.

8. O'Connell MJ. Prediction of work following traumatic brain injury: intellectual, memory, and demographic variables. Rehabil Psychol 2000;45:212-7.

9. Wall JR, Niemczura JG, Rosenthal M. Community-based training and employment: an effective program for persons with traumatic brain injury. NeuroRehabilitation 1998;10:39-50.

10. Bell KR, Sandel ME. Brain injury rehabilitation. 4. Postacute rehabilitation and community integration. Arch Phys Med Rehabil 1998;79(Suppl 1):S21-5.

11. Crisp R. Return to work after traumatic brain injury. J Rehabil 1992;58(4):27-33.

12. Lubusko AA, Moore AD, Stambrook M, Gill DD. Cognitive beliefs following severe traumatic brain injury: association with postinjury employment status: Brain Inj 1994;8:65-70.

13. Anthony WA, Brown MA, Rogers ES, Derringer S. A supported living/supported employment program for reducing the number of people in institutions. Psychiatr Rehabil J 1999;23(1):5-23.

14. Bond GR, Dietzen LL, Vogler K, Katuin CH, McGrew JH, Miller LD. Towards a framework for evaluating cost and benefits of psychiatric rehabilitation: three case examples. J Vocational Rehabil 1995;5:75-88

15. Danley KS, Rogers ES, MacDonald-Wilson K, Anthony W. Supported employment for adults with psychiatric disability: result of an innovative demonstration project. Rehabil Psychol 1994;39: $269-76$.

16. Wehman P, Kreutzer J, West M, et al. Employment outcomes for persons following traumatic brain injury: pre-injury, post-injury, and supported employment. Brain Inj 1989;3:397-412.

17. Wehman P, Kreutzer J, West M, et al. Return to work for persons with traumatic brain injury: a supported employment approach. Arch Phys Med Rehabil 1990;71:1047-52.

18. Wehman P, West M, Kregel J, Sherron P, Kreutzer J. Return to work for persons with severe traumatic brain injury. A data-based approach to program development. J Head Trauma Rehabil 1995; 10(1):27-39.

19. Rehabilitation Act, Pub L No. 99-506, 100 Stat 1845 (1986).

20. Shafer MS, Wehman P, Kregel J, West M. National supported employment initiative: a preliminary analysis. Am J Ment Retard 1990;95:316-27.

21. Kregel J, Wehman P, Revell G, Hill J, Cimera R. Supported employment benefit-cost analysis. J Vocational Rehabil 2000;14: $153-61$.

22. Rogers SE. Cost-benefit studies in vocational services. Psychiatr Rehabil J 1997;20(3):25-33.

23. Rogers SE, Sciarappa K, MacDonald-Wilson K, Danley K. A benefit-cost analysis of a supported employment model for persons with psychiatric disabilities. Eval Program Plann 1995;18: $105-15$. 
24. Thompson L, Powers G, Houchard B. The wage effects of supported employment. J Assoc Persons Severe Handicaps 1992; 17(2):87-94.

25. Shearn J, Beyer S, Felce D. The cost-effectiveness of supported employment for people with severe intellectual disabilities and high support needs: a pilot study. J Appl Res Intellect Disabil 2000;13:29-37.

26. McCaughrin WB, Ellis WK, Rusch FR, Heal LW. Cost-effectiveness of supported employment. Ment Retard 1993;31:41-8.

27. Cimera R. Are individuals with severe mental retardation and multiple disabilities cost-effective to serve via supported employment programs? Ment Retard 1998;36:280-92.

28. Hill ML, Banks PD, Handrich RR, Wehman PH, Hill JW, Schafer MS. Benefit-cost analysis of supported competitive employment for persons with mental retardation. Res Dev Disabil 1987;8:7189.

29. Wehman P, Kregel J, West M, Cifu D. Return to work for patients with traumatic brain injury: analysis of costs. Am J Phys Med Rehabil 1994;73:280-2.

30. West M, Wehman P, Kregel J, Kreutzer J, Sherron P, Zasler N. Costs of operating a supported work program for traumatically brain-injured individuals. Arch Phys Med Rehabil 1991;72:127 31.

31. Clark RE, Bush PW, Becker DR, Drake RE. A cost-effectiveness comparison of supported employment and rehabilitative day treatment. Admin Policy Ment Health 1996;24:63-77.

32. Wehman P, Grant R, Kregel J. Supported employment: a decade of rapid growth and impact. Am Rehabil 1998;Spring:31-43. 